\title{
Evaluation of Immunization Services in high-risk district in India
}

\author{
Giridhara R Babu ${ }^{1,2 *}$, Jørn Olsen ${ }^{3}$, Sayantee $\mathrm{Jana}^{4}$, Siddhartha Nandy ${ }^{5}$, Muhammad N Farid ${ }^{6}$, \\ Sadhana $\mathbf{S M}^{7}$, Shridhar Kadam ${ }^{8}$
}

\begin{abstract}
${ }^{1}$ Department of Epidemiology, School of Public Health, University of California, Los Angles, CA 90024, USA. ${ }^{2}$ Public Health Foundation of India, Indian Institute of Public Health - Hyderabad, Plot no \# 1, Anv Arcade, Amar Co-op Society, Kavuri Hills, Madhapur, Hyderabad 500081. ${ }^{3}$ Department of Epidemiology, School of Public Health, University of California, Los Angles, CA 90024. USA. Indian institute of public health, Public Health Foundation of India, Campus of Indian Institute of Health and Family welfare, Vengalrao nagar, Hyderabad 500038, India. Indian institute of public health, Public Health Foundation of India, Campus of Indian Institute of Health and Family Welfare, Vengalrao nagar, Hyderabad 500038, India. ${ }^{6}$ Department of Epidemiology, School of Public Health, University of California, Los Angles, CA 90024, USA. ${ }^{7}$ Victoria foundation, JP Nagar, Bangalore 560078, India. ${ }^{8}$ Indian Institute of Public Health, Bhubaneshwar, India
\end{abstract}

\section{A B STRACT}

The study was aimed at evaluating immunization coverage against Tuberculosis, Poliomyelitis, Diphtheria, Tetanus, Pertussis and Measles. The data was taken from a sufficiently large study that adopted multi stage and systematic random sampling. The current paper aims at reporting the evaluated coverage in Bellary district and discusses addressing gaps in coverage of vaccine preventable diseases. We have reported in our earlier papers that parental recall was better than immunization card for reflecting immunization coverage, and improvement in immunization coverage was due to special immunization sessions (catch up sessions) and supportive supervision. In this paper, we present the estimates of vaccine coverage under national program. We also discuss the shortfalls responsible for drop in immunization coverage.

Key words: Evaluation of Immunization coverage, Parental recall, Routine Immunization.

\section{INTRODUCTION}

Smallpox was declared eradicated in 1975 subsequent to effective vaccination programs and strengthened surveillance for the disease. The success of Smallpox led to launching of the Expanded Programme on Immunization (EPI) in India in 1978 to control other Vaccine Preventable Diseases (VPD). In 1978, EPI coverage was included for six diseases: diphtheria, pertussis, tetanus, poliomyelitis, typhoid and childhood tuberculosis. The aim of EIP was to cover $80 \%$ of all infants. Subsequently, the programme was universalized and renamed as Universal Immunization Programme (UIP) in 1985. Measles vaccine was included in the programme

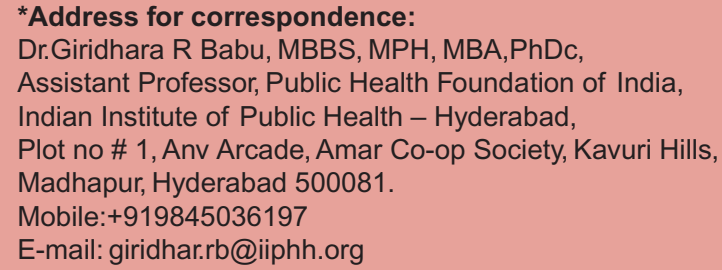

DOI: 10.5530/ijmedph.3.2011.4 and typhoid vaccine was discontinued. The UIP was introduced in a phased manner from 1985 to cover all districts in the country by 1990, targeting all infants with the primary immunization schedule and all pregnant women with Tetanus Toxoid immunization. ${ }^{1-2}$

Earlier evaluations of routine Immunization in India have shown wide differences between reported coverage by local health agencies compared to evaluated coverage..$^{[3-6]}$ Hence, it is important to ascertain the evaluated immunization coverage for all the vaccines used in UIP and to determine if there is any improvement in terms of immunization coverage. Identification of reliable source of Immunization history is important to evaluate Immunization coverage in developing countries like India. Our study aims at evaluating the sources of data in a high-risk district in Karnataka, India.

\section{OBJECTIVE}

Our objective is to evaluate the coverage of immunization antigens in the district of Bellary. 


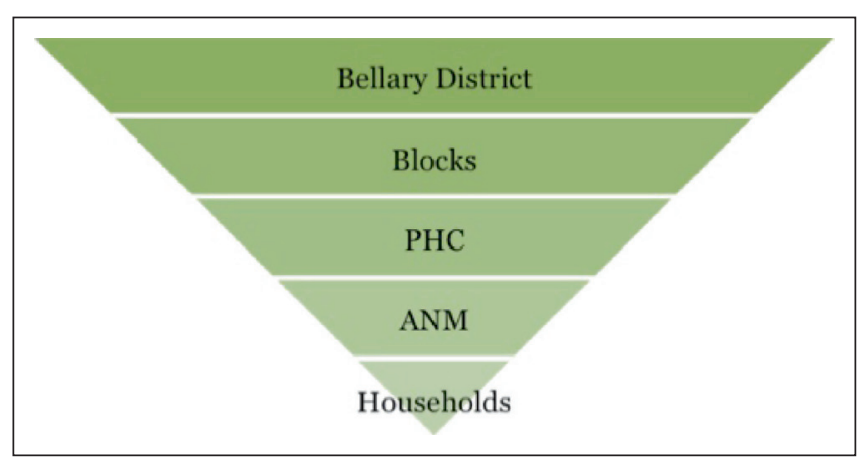

Figure 1

\section{METHODS}

We chose the district of Bellary, which had 18 confirmed cases of Poliomyelitis in the year 2003. It was reported that failure to implement routine immunization services was predominant reason for emergence of polio transmission in many districts like Bellary in India. This community-based study of children aged 0-2 years was carried out in Bellary district during the month of September 2007. Multistage cluster sampling was used for the selection of sample. We collected complete list of taluks (administrative blocks in district) and villages in Bellary district. After considering different sample designs, ${ }^{7-10}$ The study used a multi stage random cluster sample of children in the age group of 0-12 months for collection of data. All the taluks were included for the study. In the first stage, two primary health centres (PHC) were selected in each Taluk based on randomly selected number from random table. In the second stage, in each of the PHC, two villages were randomly selected from the list of villages using random number table. In the third stage, the surveyors would pick up the first house randomly and then would interview 20 houses in the following manner: First house will be selected based on the random method of picking up houses. The guideline for picking the first house was that pick any house randomly from the micro plan prepared for the purposes of implementing polio special immunization rounds (SIAs). The micro plans for SIAs are updated every round and are expected to be complete for all the villages.

The eligibility criterion for the selection was any house having at least one child birth in the last two years. Thus the study period will comprise of calendar years starting from $1^{\text {st }}$ April 2005 till 31 ${ }^{\text {st }}$ March 2007. From the first house, every $3^{\text {rd }}$ house visited in the entire village adding up to 20 houses. If any house do not contain any live births in the past two years, the next house will be selected based on the eligibility criterion.

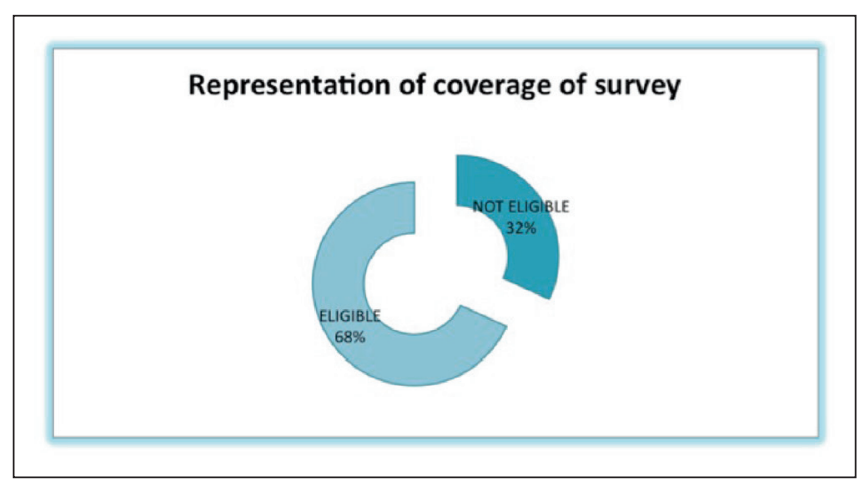

Figure 2

After identification of the houses to be surveyed, the adult individuals in the identified houses would provide complete information regarding the conduct of study. A brochure containing the details of the study will be handed over to them. Consent will be taken after duly explaining the objectives, methods and implications of the study. The participation in the study was voluntary and the subjects could have withdrawn from the study at any point of time during the survey.

All the eight taluks of Bellary were included in the study. By random sampling, however, 1632 houses were surveyed in the seven sub districts of Bellary district, Karnataka. After data check and validation, a total of 1632 parent's response was included in the survey data. The data corresponds to information about 1632 children residing in Bellary district, Karnataka.

In each of this village the surveyors would interview 20 houses in the following manner: First house will be selected based on the random method of picking up houses. Eligibility criterion for the selection of any house will be: House having at least one child birth in the last two years. Thus the study period will comprise of calendar years starting from $1^{\text {st }}$ April 2005 till $31^{\text {st }}$ March 2007. From the first house, every $3^{\text {rd }}$ house visited in the entire village adding up to 20 houses. If any house did not contain any live births in the past two years, the next house will be selected based on the eligibility criterion.

The analysis was done at University of California, Los Angeles with permission of IRB from University of California Los Angeles for data analysis.

\section{Sources of Data}

First, the collection of information about immunization history was sought from interviews of parents. Second, the information regarding immunization was also obtained independent of the information through interview, by cross checking the details on immunization cards of children. 
Third, in the event where immunization cards are not available, the same details were obtained by Immunization register maintained in each village by the ICDS worker present in the village. Finally, the information for BCG scar was obtained by cross checking the BCG scar present generally on the lateral side of the left arm. This too was obtained independent of information obtained from the interviews. The information obtained by first above was classified as parental recall, second and third were classified as card and fourth was classified as scar.

\section{Data entry and analysis}

All the information obtained was entered in a master sheet corresponding to the village by the interviewer. The coded information was entered village wise in Microsoft excel. The names and all other personal identification measures were removed from the data before data analysis. Initial data analysis was performed using SPSS for Windows (Rel. 11.0.1. 2001. 17.0, R 2.11. Chicago: SPSS Inc). The output for this paper was generated using SAS software.

(Copyright, SAS Institute Inc. SAS and all other SAS Institute Inc. product or service names are registered trademarks or trademarks of SAS Institute Inc., Cary, NC, USA)

\section{RESULTS}

Out of the 1630 children were surveyed, we included only 1110 children between 9-24 months of age for our study.

We assessed immunization coverage according to the source of data: on the basis of card alone, on the basis of BCG Scar and card; and on the basis of parental recall. On analyzing information in cards, it was found that around 98\% children received all the doses except measles whose coverage was $96 \%$. According to card, complete immunization was found to be $96 \%$. On the basis of parent's recall about their child's immunization status, the coverage of complete

\begin{tabular}{lll}
\multicolumn{3}{l}{ Table 1: National immunization shedule-India } \\
\hline Beneficiary & \multicolumn{1}{c}{ Age } & \multicolumn{1}{c}{ Vaccine } \\
\hline Infants & Birth & BCG* and OPV** $^{*}$ \\
& 6 weeks & DPT \& OPV \\
& 10 weeks & DPT \& OPV \\
& 14 weeks & DPT \& OPV \\
& 9 months & Measles vaccine \\
& 18 months & DPT \& OPV (Booster dose) \\
Children & 5 years & DT vaccine \\
& 10 years & Tetanus Toxoid \\
& 16 years & Tetanus Toxoid \\
\hline
\end{tabular}

*At birth or at the time of DPT/OPV

**dose called as Zero dose and can be given till 14 days of age, if missed early. Abbreviations: $B C G$ = Bacillus calmittee Guerin; DPT = Diphtheria, Pertussis \& Tetanus; OPV = Oral Polio Vaccine; DT = Diphtheria \& Tetanus vaccine. immunization was $86.5 \%$. The difference between these two sources of data is significant since the confidence intervals are non- overlapping.

The inter-dose drop-out rates for antigens are almost similar for same source of Data, and the common point for both data sources is that the maximum drop out occurs in the time period between DPT3/OPV3 to Measles. (Figure 3). This suggests that the maximum drop out occurs in the time period between DPT3/OPV3 to Measles. DPT and OPV are given at monthly intervals and Measles is administered at 9 completed months since birth.

\section{DISCUSSION}

There is considerable literature available on evaluation of Immunization coverage in different areas of India. ${ }^{11-20}$ Our earlier study ${ }^{21}$ showed that the information from parental recall is comparable to the data from BCG scar for BCG, and has higher specificity compared to Immunization cards. ${ }^{22-23}$

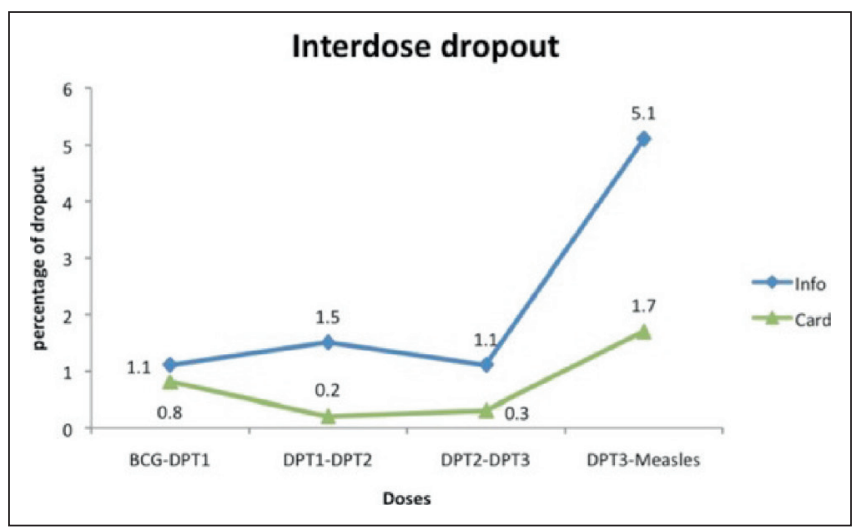

Figure 3

\begin{tabular}{lc} 
Table 2: Composition of Survey subjects \\
\hline \multicolumn{1}{c}{ Total number of individual surveyed } & Number \\
\hline All children & 1630 \\
Girls & 830 \\
Boys & 790 \\
Ratio (Girl : Boy) & 1.05 \\
Eligibility criterion for complete immunization & 1110 \\
(Children of age [9, 24] months) & \\
Girls & 548 \\
Boys & 562 \\
Immunization Card Holder & 888 \\
Girls & 460 \\
Boys & 428 \\
\hline
\end{tabular}




\begin{tabular}{|c|c|c|c|}
\hline & Antigen Dose & Estimates & Confidence intervals \\
\hline Immunization card retention & & 82.7 & $(80.41,84.95)$ \\
\hline \multirow[t]{18}{*}{ Immunization system access } & OPV 0 & 67.9 & $(65,70.78)$ \\
\hline & BCG parental recall & 94.35 & $(92.84,95.86)$ \\
\hline & BCG card & 98.4 & $(97.57,99.23)$ \\
\hline & BCG scar & 92.44 & $(90.85,94.04)$ \\
\hline & DTP 1 parental recall & 94.7 & $(93.16,96.25)$ \\
\hline & DTP 1 card & 98.24 & $(97.36,99.13)$ \\
\hline & OPV 1 parental recall & 94.61 & $(93.06,96.16)$ \\
\hline & OPV 1 card & 98.6 & $(97.8,99.38)$ \\
\hline & DTP 2 parental recall & 93.88 & $(92.23,95.53)$ \\
\hline & DTP 2 card & 98.57 & $(97.77,99.37)$ \\
\hline & OPV 2 parental recall & 94.01 & $(92.38,95.64)$ \\
\hline & OPV 2 card & 98.57 & $(97.77,99.37)$ \\
\hline & DTP 3 parental recall & 92.98 & $(91.21,94.74)$ \\
\hline & DTP 3 card & 98.32 & $(97.44,99.19)$ \\
\hline & OPV 3 parental recall & 93.11 & $(91.35,94.87)$ \\
\hline & OPV 3 card & 98.29 & $(97.41,99.18)$ \\
\hline & Measles parental recall & 87.31 & $(84.89,89.72)$ \\
\hline & Measles card & 96.62 & $(95.32,97.92)$ \\
\hline \multirow[t]{4}{*}{ Complete Immunization } & Scar and Card & 93.22 & $(91.36,94.08)$ \\
\hline & All Card & 95.95 & $(94.51,97.4)$ \\
\hline & Parental recall & 86.5 & $(83.96,89.09)$ \\
\hline & Scar and recall & 82.67 & $(79.82,85.52)$ \\
\hline
\end{tabular}

Our study submitted earlier elsewhere ${ }^{21}$ compared sources of data with BCG scar as gold standard, whereas earlier studies have used either Immunization cards ${ }^{11}$ or prospective history as gold standard. Developing countries like India may not consider either Immunization card or prospective history as gold standard to compare other data sources since these countries have ineffective immunization card utilization absence of any reliable registry data. BCG vaccination offers unique opportunity to cross check reliability of other data sources by permanent scarring. The absence of such gold standards for other antigens makes it difficult for such comparisons. In the absence of parental recall, use of modern epidemiological methods can be made for estimation of immunization coverage. ${ }^{24-28}$ Hence in this paper, we have submitted the comparisons of evaluated coverage's of VPD antigens by both sources of data comparing the gold standard.

Our earlier papers have demonstrated that "supportive supervision" and implementation of "special "catch-up" immunization sessions (conducted in Bellary district during the months of July and August of the year 2007) were responsible for the improvement in immunization coverage..$^{29-30}$ Complete immunization is defined as the completion of BCG dose at birth (or later), three doses of DPT and OPV with 4 weeks gap in between Measles before the age of 1 year. Based on this, and our earlier study, we have relied on information from parental recall. Information from parental recall provides realistic and more conservative improvements in coverage for all antigens compared to information from the cards. We found that the improvement in immunization coverage was due to special immunization sessions (catch up sessions) and enhanced supervision due to the newly implemented Immunization programme under Reproductive and Child Health Project-II of Government of India. Our study found poor state and district level supervision as the predominant reason for the poor immunization coverage against vaccine preventable diseases. Other reasons include ineffective plan for social mobilization and the inability of local Governments to improve routine immunization services in the high-risk areas. In the absence of other external evaluations, the District Level Household survey (DLHS) conducted by National Family Health Survey in 2006 can be taken as background immunization rate in the district. DLHS-1 was conducted in the years 1998-99 and DLHS-2 was conducted in the years 2002-04.

Further, steps should be taken to address missing children for follow-up between DPT3/OPV3 to Measles as maximum drop out occurs in this period.

\section{CONCLUSION}

We have reported the evaluated coverage for several antigens including inter-dose dropouts for several antigens. 


\section{REFERENCES}

1. Government of India. National Child Survival and Safe Motherhood Programme. New Delhi: Ministry of Health and Family Welfare; 1994.

2. Patowary A, Jaiswal O, Lal S, Govila A, Pratinidhi A, Sharma A, Swain S, Gupta S, Joseph A, Sawhney N, Chakraborty A, Maitra K, Chandrasekhar C, Mathur A, Saxena N, Saxena B. Coverage Evaluation Survey Of Immunization In Eleven States Of India.Indian J Community Med 1990; 15:222-226.

3. Lim SS, Stein DB, Charrow A, Murray CJ. Tracking progress towards universal childhood immunisation and the impact of global initiatives: a systematic analysis of three-dose diphtheria, tetanus, and pertussis immunisation coverage. Lancet2008; 372:2031-46.

4. Coutinho L, Bisht S, Raje G. Numerical narratives and documentary practices: vaccines, targets and reports of immunisation programme. Econ Polit Wkly2000; 35:656-66.

5. Sokhey J. The Immunization Programme In India. Indian J Community Med 1990; 15:163-172.

6. Mukherjee B, Ray SK, Kar M et al. Coverage evaluation surveys amongst children in some blocks of West Bengal. Ind J Pub Health. 1990; 34(4); 209-14.

7. Bennett $A$ et al. A computer simulation of household sampling schemes for health surveys in developing countries. International Journal of Epidemiology, 1994, 23:1282-1291.

8. Harris DR, Lemaeshow S. Evaluation of the EPI survey methodology for estimating relative risk. World Health Statistics Quarterly, 1991, 44:107-113.

9. Lemeshow $S$, Robinson D. Surveys to measure programme coverage and impact: a review of the methodology used by the Expanded Programme on Immunization. World Health Statistics Quarterly, 1985, 38:65-75.

10. Reichler MR et al. Cluster survey evaluation of coverage and risk factors for failure to be immunized during the 1995 National Immunization Days in Egypt. International Journal of Epidemiology, 1998, 27:1083-1089.

11. Singh $\mathbf{P}$ and Yadav R.J. Immunization status of children of India. Indian Pediatric 2000; 37:1194-1199.

12. Suresh K, Saxena D. Trends and determinants of immunization coverage in India. J Indian Med Assoc 2000; 98:10-14.

13. International Institute for Population sciences (IIPS) and ORC Macro.1994 National Family Health Survey (NFHS-1), 1992-1993: India. Mumbai: IIPS.

14. International Institute for Population sciences (IIPS) and ORC Macro. 2000. National Family Health Survey (NFHS-2), 1998-1999: India. Mumbai: IIPS.

15. Bhatia V, Swami HM, Rai SR, Gulati S, Verma A, Parashar A, Kumari R. Immunization status in children. Indian J Pediatr 2004 Apr; 71(4):313-315.

16. Kar M, Reddiah VP, Kant S. Primary immunization status of children in slum areas of South Delhi- the challenge of reaching urban poor. Indian J Community Med 2001; 26:151-154.
17. Singh P, Yadav RJ. Immunisation status of children in BIMARU states. Indian J Pediatr 2001 Jun; 68(6):495-500.

18. Ray SK, Dasgupta S, Dobe M, Biswas R, Mehta P, Baishya AC. An evaluation of routine immunization coverage in some districts of West Bengal and Assam. Ind J Pub Hlth 2004; 48:82-85.

19. Singh MC, Badole CM, Singh MP. Immunization coverage and the knowledge and practice of mothers regarding immunization in rural area. Indian J Pub HIth 1994; 38:103-107.

20. Tandon BN, Gandhi N. Immunization coverage in India for areas served by the Integrated Child Development Services programme. The Integrated Child Development Services Consultants. : Bull World Health Organ1992; 70:461-465.

21. Giridhara R Babu, Jorn Olsen, Sayantee Jana ,Siddhartha Nandy, Muhammad Farid, VJ Sadhana. Evaluation of Immunization Cards And Parental Recall Against Gold Standard For Evaluating Immunization Coverage. The Internet Journal of Epidemiology. 2011 Volume 9 Number 2 web: IJE.

22. Singh : Record-Based Immunization Coverage Assessment in Rural North India The Internet Journal of Third World Medicine. 2007 Volume 4 Number 1.

23. Jishnu Das, Saumya Das, Trust, learning, and vaccination: a case study of a North Indian village, Social Science and Medicine, Volume 57, Issue 1 , July 2003, Pages 97-112.

24. Boerma, J. T., Sommerfelt, S., Rutstein, S., Rojas, G. (1990) Immunization: Levels, Trends and Differentials. Comparative Studies No. 1. Demographic and Health Surveys. Institute for Resource Development, Columbia.

25. Giridhara R Babu (2008). Comment on 'From risk factors to explanation in public health'. J Public Health, 30:515-516.

26. Greenland S, Neutra R (1980). Control of confounding in the assessment of medical technology. Int J Epidemiol,9:361-367.

27. Greenland S, Lash TL (2008). Bias Analysis. In: Rothman KJ, Greenland S, Lash TL (ed). Modern Epidemiology, $3^{\text {rd }}$ edn. Lippincott Williams and Wilkins, Philadelphia, pp 348-352.

28. Rothman KJ, Greenland S, Lash TL (2008). Precision and statistics in epidemiologic studies. In: In: Rothman KJ, Greenland S, Lash TL (ed). Modern Epidemiology, $3^{\text {rd }}$ edn. Lippincott Williams and Wilkins, Philadelphia, pp 132-34.

29. Giridhara R Babu, Vivek V Singh, Sadhana SM, Siddhartha Nandy, Sayantee Jana, Sathyanarayana TN. Supportive supervision and Immunization Coverage: Evidence from India. The Internet Journal of Epidemiology. 2011 Volume 9 Number 2. The Internet Journal of Epidemiology. 2011 Volume 9 Number 2. Web: Internet Journal of Epidemiology.

30. Giridhara R Babu, Sayantee Jana, Siddhartha Nandy, Jørn Olsen, Muhammad N Farid, Sadhana SM. Role of Catch-up campaign in Developing countries: A success story from India. Annals of Tropical Medicine and Public Health [Under peer review]. 